\title{
Most Impacting Injuries in Football: a Possible Association?
}

\author{
M. Glaied ${ }^{1}$, G. N. Bisciotti ${ }^{2}$, A. Bisciotti ${ }^{3}$, A. Bisciotti ${ }^{3}$, C. Eirale ${ }^{2}$ \\ ${ }^{1}$ Qatar Orthopaedic and Sport Medicine Hospital, Doha, Qatar \\ ${ }^{2}$ Paris Saint Germain FC, Paris, France \\ ${ }^{3}$ Kinemove Rehabilitation Center, Pontremoli, Massa-Carrara, Italy
}

\section{CORRESPONDING AUTHOR:}

Bisciotti Gian Nicola

Paris Saint Germain Football Club

Avenue Kennedy 1

Saint Germain en Laye

Paris, France

E-mail: bisciotti@libero.it

DOI:

10.32098/mltj.02.2021.20

LEVEL OF EVIDENCE: 4

\begin{abstract}
SUMMARY
Objective. Epidemiological studies on soccer injuries show that anterior cruciate ligament, groin, and hamstring injuries are heavily impacting availability, therefore medical research has focused on them. A certain number of studies have focused on the possible association between these three injuries. The aim of this study is to describe the possible association between these three injuries and to discuss their possible logical association.

Methods. This study is based on the injury records of four international Qatar league players who suffered all these three injuries during their career. Our hypothesis is that these three injuries are related to each other through a cause-effect mechanism.

Results. Based on the observational data of this study, the hypothesis that the anterior cruciate ligament, groin and hamstring injuries may be associated with each other can be advanced. This hypothesis is based on both anatomical and functional justifications. Conclusions. Being our knowledge of the pathophysiology and factors predisposing athletes to muscle, tendon and articular injury is still limited, the consequences of another type of injury on the athlete's overall injury risk profile have probably been underestimated or not correctly understood. Further studies are necessary to clarify this cause-effect relation and this study also represents a call for action for future researches in this area.
\end{abstract}

\section{KEY WORDS}

ACL injury; hamstring injury; groin injury; injuries association; intrinsic-extrinsic risk factors.

\section{INTRODUCTION}

Anterior cruciate ligament (ACL) injury, groin pain syndrome (GPS) and hamstring injury (HI) are heavily impacting availability in sprinting and cutting sports activity, particularly in soccer, when time loss value is considered $(1-4)$. In soccer, $\mathrm{HI}$ is the most frequent muscle injury and accounts for $39.5 \%$ of all muscle injuries, followed by GPS that represents $25.6 \%$ of all injuries (4), whereas ACL injuries count 0.66 events per 1000 hours of total exposure time (i.e., 0.5 ACL per team per season) (5). In Australian football, the most common and prevalent injury proved to be HI followed by ACL and GPS (6) with these three injuries causing a total percentage of missed games equal to $21.2 \%$ for HI, $12.8 \%$ for ACL injuries and $11.9 \%$ for GPS (6).
Furthermore, found that, in Australian football (7), HI causes a loss of 21 games per team per season (i.e., 6.1 injuries per team per season) followed by GPS with 16 games lost per team per season (i.e., 3.9 injuries per team per season) and ACL injury with 12 games lost per team per season (i.e., 0.7 injuries per team per season). Despite the fact that the majority of studies in literature consider the etiopathogenesis of these three injuries to be independent, recent studies consider a possible association between them (7-10). However, the results of these studies are conflicting. Indeed, several studies show that $\mathrm{HI}$ could be a risk factor for ACL injury (9); ACL injuries and GPS could be risk factors for HI (11) and GPS could be a risk factor for HI (8). On the contrary, Toohey et al. (10) affirmed no association between GPS and HI. This lack of consensus in literature prevents us 
from being able to answer two fundamental questions with certainty: is there a connection between these three injuries? Do these three injuries have a common intrinsic risk factor? In this study, we present 4 cases where there is an association of these three injuries. The data, obtained from professional football players playing both in the Qatar first division (Star League) and in the Qatar National Team, were collected by medical and physiotherapic staff through an informatics recording system and confirmed. All the interested subjects were informed of the purpose of the research and signed an informed consent. The aim of this study is to describe the possible association between these three injuries and to discuss their possible logical association. The research is ethically according to international standards and as required by the journal (12). Furthermore, the study was conducted following the I.S.MuL.T. Guidelines for muscle injuries (13).

\section{Case 1}

BM, a 30-year-old professional football player, suffered from GPS due to posterior abdominal wall weakness (September 2007) and twice (October 2009 and March 2010) from adductor-related GPS. The posterior abdominal wall weakness was treated surgically by the "minimal repair technique" (14), while the first episode of adductor-related GPS underwent conservative treatment and the second was surgically treated by a bilateral tenotomy of the adductor longus. The player resumed sports activity after 8 weeks following minimal repair surgery, after 4 weeks following the adductor-related GPS conservative treatment, and after 24 weeks following tenotomy (15). Furthermore, this player suffered from grade III right $\mathrm{HI}$ in February 2011 which was treated with physiotherapy and sports activity was resumed after 8 weeks. Finally, the player suffered two ACL injuries (right knee in August 2014 and left knee in September 2018); both injuries occurred during a contact situation and were treated with hamstring autograft surgery. After the first ACL injury, the player returned to play after 28 weeks, whereas after the second ACL injury, return to play occurred after 36 weeks.

\section{Case 2}

LP, a 35-year-old professional football player suffered an ACL right knee injury during a non-contact situation in December 2009: surgical reconstruction (hamstring autograft) was carried out and the player returned to full sports activity after 28 weeks. Later, LP suffered GPS due to posterior inguinal wall weakness for which laparoscopic mesh placement was undergone (October 2014). Sports activity was resumed 12 weeks after surgery. In March 2015, LP suffered a bilateral adductor-related GPS that underwent conservative treatment and return to play was possible after 2 weeks. Finally, LP suffered grade II right HI in October 2018 and in September 2018, both injuries were treated conservatively and, in both cases, return to play was possible after 6 weeks.

\section{Case 3}

MJ, a 32-year-old professional football player, suffered a right ACL non-contact injury in January 2008 which was surgically treated (hamstring autograft) and a second ipsilateral non-contact ACL injury in November 2008, which also treated with surgery (patellar tendon autograft). After the first ACL reconstruction, the player returned to full sports activity after 24 weeks, whereas after the revision ACL reconstruction, he resumed full sports activity after 40 weeks. Later, MJ suffered a bilateral GPS in July 2012 due to a posterior inguinal wall weakness and underwent bilateral minimal repair surgery (14): return to full sports activity was possible after 8 weeks. Finally, MJ suffered two HI, initially in the right leg in April 2015, and then in the contralateral limb in March 2017. Both the injuries were grade II and were conservatively treated: return to the sports activity was possible after 4 and 3 weeks respectively.

\section{Case 4}

BK, a 31-year-old professional football player, experienced a non-contact right ACL injury in April 2007. The player later experienced a second ipsilateral non-contact ACL injury in April 2009. Both injuries were treated surgically with a patellar autograft (April 2007) and a hamstring autograft (April 2009) respectively and consequently, return to play was possible after 20 months and 36 weeks respectively. Later, the player experienced a grade II right HI in February 2012. The injury was dealt with conservative treatment and after 3 weeks the player returned to sports activity. In July 2015, the player then experienced GPS due to posterior inguinal wall weakness and underwent minimal repair surgery (14): the player returned to sports activity after 12 weeks. In January 2017, the player experienced another grade II HI, resolved with conservative treatment and return to sports activity was possible after 3 weeks.

The chronology and the kind of injuries are resumed in table I.

\section{DISCUSSION}

This study provides a concrete example of how, within the context of a career in soccer, ACL injury, HI and GPS may be 
Table I. The chronology and type of injuries in the four cases considered.

\begin{tabular}{llll}
\hline PLAYER 1 & PLAYER 2 & PLAYER 3 & PLAYER 4 \\
\hline GPS (September 2007) & ACL (December 2009- right) & ACL (January 2008- right) & ACL (April 2007- right) \\
\hline GPS (October 2009) & GPS (October 2014) & ACL (November 2008 right) & ACL (April 2009- right) \\
\hline GPS (March 2010) & GPS (March 2015) & GPS (July 2012) & Hamstring (February 2012) \\
\hline Hamstring (February 2011) & Hamstring (October 2018) & Hamstring (April 2015) & GPS (July 2015) \\
\hline ACL (August 2014- right) & Hamstring (September 2018) & Hamstring (March 2017) & Hamstring (January 2017) \\
\hline ACL (September 2018-left) & & & \\
\hline
\end{tabular}

linked. It is difficult, based on actual evidence, if not impossible, to try to explain this connection in terms of a cause-effect relationship. Indeed, even though a certain number of studies have shown that a correlation exists between some injuries and a previous injury, our understanding of pathophysiology and the factors that predispose to injury are still limited (9). However, based on current literature, we can try to explain a rationale underlying the association between these three types of injury and anticipate future hypotheses.

\section{Previous $\mathrm{ACL}$ injuries and $\mathrm{HI}$}

Several authors (7) reported that, in Australian football, a history of ACL lesion triggered an odds ratio of $5.6(95 \%$ CI, 1.1-28.1) for experiencing a future HI. Other studies (10) showed that athletes who had suffered an ACL injury during their career had more than twice the chance of incurring a HI compared to athletes without a history of ACL injury (RR: $2.25,95 \%$ CI 1.34 to 3.76). Moreover, it is worth noting that several authors (11) demonstrate that the chance of incurring $\mathrm{HI}$ a second time increases almost four-fold if an athlete has already suffered an ACL injury. In two studies $(8,11)$ the graft technique employed in the consequent reconstruction (patellar tendon autograft or hamstring autograft) was not associated with subsequent HI. This concept contradicts the hypothesis formulated by other authors (16) in which HI, subsequent to ACL reconstruction, was seen to depend on the type of graft used, the harvesting procedure used for the hamstring autograft (17) and the residual hamstring weakness following hamstring autograft (16). The most plausible hypothesis seems to be that harvesting hamstrings for ACL reconstruction lays them open to risk subsequent injury due to iatrogenic damage per se and the consequent imbalance between lateral (biceps femoris) and medial (semitendinosus) hamstrings $(16,17)$. Even when a patellar tendon autograft is used for ACL reconstruction, this association may be explained by the fact that ACL injury and the subsequent rehabilitation programme alter the biomechanics of the lower limb causing an increased risk of $\mathrm{HI}(8,9)$.
In this study, correlation between previous ACL injuries and $\mathrm{HI}$ can be found in cases 2,3 and 4. The athlete described in case 2 underwent an initial ACL reconstruction with hamstring autograft. The case 3 athlete underwent an initial ACL reconstruction with hamstring autograft and a revision ACL reconstruction with patellar tendon autograft, whereas the athlete described in case 4 first underwent ACL reconstruction with patellar tendon autograft and then a revision ACL reconstruction with hamstring autograft.

\section{Previous $\mathrm{HI}$ and $\mathrm{ACL}$ injuries}

ACL injury classically occurs when the foot locks to the ground with concurrent low knee flexion angle, knee joint rotation, and excessive valgus stress (18). In this biomechanical situation, the femoral shear forces above the tibia increase, resulting in an anterior tibial translation which, in turn, causes ACL elongation (19). During non-contact ACL injuries, this situation typically occurs when changing direction or during sidestep cutting maneuvers $(18,20,21)$. Several studies show that, in such situations, the hamstring and quadriceps electromyographic activity increases significantly $(20,22)$. The correct balance between hamstring- and quadriceps- activation plays a paramount role in the correct kinematics of these situations $(20,22)$. Indeed, a reduction in hamstring activity compared to the quadriceps, reduces the knee flexion angle and increases the ground reaction force on the knee-joint (18). For this reason, correct hamstring neuromuscular function is a critical aspect of ACL injury prevention (18). When changes in direction or sidestep cutting occur during running, it is interesting to note that the three muscles composing the hamstring group act differently: the semitendinosus and the semimembranosus control internal rotation and the varus stress, whilst the biceps femoris control external rotation and the valgus stress $(18,20,21)$. Therefore, functionality impairment of the lateral- (semitendinosus and the semimembranosus muscles) or medialhamstring (biceps femoris) represents a risk factor for ACL injury (9). In other words, optimal hamstring functionality 
is an important prevention factor for ACL injury. It clearly emerges from current literature that a past $\mathrm{HI}$ causes an alteration in lower limb muscular functionality compared with the contralateral uninjured limb. Several studies show the following neuromuscular mal-adaptation after $\mathrm{HI}$ :

1. lower eccentric knee flexor strength $(10 \%-24 \%)(23,24)$;

2. lower voluntary myoelectric activity during a maximal knee flexor eccentric contraction $(18 \%-20 \%)(25,26)$;

3. lower knee flexor eccentric rate of torque development (39\% 40\%) (27);

4. lower voluntary myoelectric activity during the initial part of eccentric contraction $(19 \%-25 \%)(23,26)$;

5. lower hamstrings/quadriceps ratio (19\%) (23).

These data show that a past episode of $\mathrm{HI}$ involves impairment of muscular functionality in the injured limb compared to the contralateral uninjured limb.

Furthermore, it is worth noting that uninjured female hamstrings, compared to uninjured male hamstrings, show:

1. lower hamstring /quadriceps strength ratios $(23,28)$;

2. lower knee flexor rate of force development during eccentric isokinetic contractions (27);

3. lower knee flexor rate of force development during isometric contraction (29);

4. lower electromyographic hamstring activity during isokinetic eccentric knee flexion $(25,26)$;

5. lower electromyographic hamstring activity during a sidestep cutting maneuver $(30)$.

These data clearly appear to overlap with those previously reported concerning the alteration of the hamstring neuromuscular function following injury: since the above data explain the elevated risk of ACL injury in women (19, 31, 33 ), it is reasonable to advance the hypothesis that, in the same way, an early episode of $\mathrm{HI}$ and the neuromuscular deficit arising, may represent a risk factor for ACL injury.

However, is important to note that the majority of these data are recorded by a single joint isokinetic test. For this reason, further studies assessing the impact of previous $\mathrm{HI}$ in knee kinematics, during movement of greater degrees of freedom, are needed to confirm the aforementioned hypothesis. Moreover, further studies concerning the different role of lateral and medial hamstrings during change in direction and cutting maneuvers are needed.

In this study, the association between earlier episodes of $\mathrm{HI}$ and ACL injuries can be found in the subject case 1 .

\section{Previous GPS and $\mathrm{HI}$}

In literature, several studies show the association between GPS and HI (7-9). A possible explanation for this association is that, after GPS, the biomechanical properties of the core muscles (i.e., the major muscles that stabilizes and controls the pressure inside the trunk) and lower limb muscles are perturbed and the possibility of the athlete incurring $\mathrm{HI}$ is increased (9). As in the association between previous ACL injuries and subsequent HI, either the GPS clinical framework itself or the subsequent rehabilitation programme (especially post-surgical rehabilitation) or, a combination of both, may cause this increased risk for HI. However, it should be pointed out that in literature two studies $(34,35)$ did not find a significant correlation between GPS and subsequent HI. It is anyway important to note that in both these studies, an exact definition of GPS was not given and only the generic term of "chronic groin pain" was offered, omitting any concept of etiopathogenesis. This obviously may lead to bias in the authors' conclusions.

Furthermore, in the scientific literature the definition of GPS in athletes is ambiguous and controversial $(36,37)$. For this reason, the hypothesis between the association of a previous GPS clinical framework and subsequent HI must be considered with care.

In this study, the association between previous GPS and HI can be found in cases 1,2 and 3.

\section{Previous $\mathrm{HI}$ and GPS}

Since the top five causes of GPS are (38): femoroacetabular impingement ( $32 \%$ of the cases), posterior wall inguinal canal weakness ( $24 \%$ of the cases), adductor-related pathologies ( $12 \%$ of the cases), inguinal-related pathologies ( $10 \%$ of the cases) and hip labral pathologies ( 5\% of the cases), it is possible to hypothesize that previous episodes of $\mathrm{HI}$ may perturb running biomechanics and unmask the onset of the clinical frameworks causing GPS as reported .

However, as already mentioned, the controversy in defining GPS $(36,37)$ must always be kept in mind as it represents a source of confusion in determining the factors that can influence the onset of this condition.

In this study, the association between previous HI and GPS can be found in subject case 4 .

\section{Previous GPS and ACL injuries}

Several authors showed the association between GPS and ACL injuries (7). It is important to note that a decreased range of motion of the hip joint, particularly internal rotation of the hip due to a cam-FAI deformity, is a risk factor for developing GPS $(36,39,40)$. by causing biomechanical stress on the posterior wall inguinal canal $(36,38,39)$. Moreover, it is known that an increased tibial internal rotation of the knee joint is considered a risk factor for ACL injuries (41). Hence, 
it is reasonable to hypothesize that, with a reduction of the hip range of motion leading to an excessive posterior wall inguinal canal stress, the knee joint also undergoes additional stress to compensate for this biomechanical situation and thus increases the tibial internal rotation (7). These changes in biomechanical stress, leading to an increased risk of ACL injury, may also exacerbate under particular conditions such as fatigue (42). In this study, an association between previous GPS and ACL injuries can be found in the players described in in cases 2, 3 and 4 .

\section{Previous ACL injury and GPS}

The same hypothesis formulated for the association between previous HI and GPS, may also be extended to the association between previous ACL injury and GPS onset. In other words, the perturbation in running biomechanics caused by a previous ACL injury, could favor the onset of the clinical framework underlying GPS (7). Furthermore, we must also consider the influence of iatrogenic damage, resulting from autograft harvesting, on the biomechanics of the pelvis in general and in particular dynamic situations such as the change in direction and cutting maneuvers $(16,17,30)$.

In this study, the association between previous ACL injury and GPS can be found in the case study 1 .

\section{Limitations of the study}

The major limitation of this study is that it is based on anecdotal examples, which obviously cannot be generalized. Although, a physiological connection between these pathologies are conceivable. For this reason, one of the messages that this study wants to promote is that of a "call for action" so further studies of greater evidence can confirm or confute the advanced hypotheses.

\section{CONCLUSIONS}

Most of the epidemiological studies have often disregarded the full picture of the athlete's history of injury. Thus,

\section{REFERENCES}

1. Hägglund M, Waldén M, Ekstrand J. Injuries among male and female elite football players. Scand J Med Sci Sports 2009;19(6):819-27.

2. Ekstrand J, Hägglund M, Waldén M. Injury incidence and injury patterns in professional football: the UEFA injury study. Br J Sports Med 2011;45(7):553-8

3. Pfirrmann D, Herbst MI, Ingelfinger P, Simon P, Tug S Analysis of Injury Incidences in Male Professional Adult and the consequences of previous injury on the athlete's overall injury risk profile have probably been underestimated or improperly understood $(10,43)$. In other words, a possible association between previous injuries, apparently unrelated both in nature and in anatomical location, can rarely be found in the literature. Despite this, some studies have recently suggested a complex interaction between what seem to be extremely distinct types of injuries. This represents an important aspect of research for the identification of causal risk factors aimed at developing effective tertiary prevention strategies. The present study, based on anecdotal data, does not claim to explain the association between the three pathologies described above but it highlights some logical hypotheses that should be confirmed by further studies. Furthermore, this study allows us to underline the fact that our understanding of the pathophysiology and factors predisposing athletes to muscle, tendon and articular injury is still limited. Therefore, above all, this study aspires to be a "call for action" for studies able to clarify the possible association between the sport injuries described herein. In the light of our own current knowledge, the most probable hypothesis is not a pathophysiology based on some common risk factors to these three types of injuries (7) but rather the hypothesis relating these injuries to each other through a cause-effect mechanism.

Given the importance of injury prevention programmes implementation, we hope for the future development of studies focusing on the correlation between the distinct types of sport injuries occurring throughout the history of an athlete.

\section{FUNDINGS}

This research did not receive any specific grant from funding agencies in the public, commercial, or not-for-profit sectors.

\section{CONFLICT OF INTERESTS}

The authors declare that they have no conflict of interests.

Elite Youth Soccer Players: A Systematic Review. J Athl Train 2016;51(5):410-24.

4. Jones A, Jones G, Greig N, Bower P, Brown J, Epidemiology of injury in English Professional Football players: A cohort study. Phys Ther Sport 2019;35:18-22.

5. Waldén M, Hägglund M, Magnusson H, Ekstrand J. ACL injuries in men's professional football: a 15-year prospective study on time trends and return-to-play rates reveals only $65 \%$ of 
players still play at the top level 3 years after ACL rupture. Br J Sports Med 2016;50(12):744-50.

6. Orchard J, Seward H Epidemiology of injuries in the Australian Football League, seasons 1997-2000. Br J Sports Med 2002;36:39-4400.

7. Verrall GM, Esterman A, Hewett TE. Analysis of the three most prevalent injuries in Australian Football demonstrates a season to season association between groin/hip/osteitis pubis injuries with ACL knee injuries. Asian J Sports Med 2014;5(3):e23072.

8. Koulouris G, Connell DA, Brukner P, et al. Magnetic resonance imaging parameters for assessing risk of recurrent hamstring injuries in elite athletes. Am J Sports Med 2007;35:1500-6.

9. Opar DA, Serpell BG. Is there a potential relationship between prior hamstring strain injury and increased risk for future anterior cruciate ligament injury? Arch Phys Med Rehabil 2014;95(2):401-5.

10. Toohey LA, Drew MK, Cook JL, Finch CF, Gaida JE. Is subsequent lower limb injury associated with previous injury? A systematic review and meta-analysis. Br J Sports Med 2017;51 (23):1670-1678.

11. Verrall GM, Slavotinek JP, Barnes PG, Fon GT, Spriggins AJ. Clinical risk factors for hamstring muscle strain injury: a prospective study with correlation of injury by magnetic resonance imaging. Br J Sports Med 2001;35(6):435-9.

12. Padulo J, Oliva F, Frizziero A, Maffulli N. Muscles, Ligaments and Tendons Journal - Basic principles and recommendations in clinical and field Science Research: 2018 update. Muscles Ligaments Tendons J 2018;8(3):305-07.

13. Maffulli N, Oliva F, Frizziero A, et al. ISMuLT Guidelines for muscle injuries Muscles Ligaments Tendons J 2013;3 (4):241-49.

14. Muschaweck U, Koch A. Sportsmen's groin: Definition, differential diagnosis and treatment. Radiologe 2019;59(3):224-33.

15. Robertson IJ, Curran C, McCaffrey N, Shields CJ, McEntee GP. Adductor tenotomy in the management of groin pain in athletes. Int J Sports Med 2011;32(1):45-8.

16. Mohtadi N, Barber R, Chan D, et al. Complications and adverse events of a randomized clinical trial comparing 3 graft types for ACL reconstruction. Clin J Sport Med 2016;26:182-9.

17. D'Alessandro P, Wake G, Annear P. Hamstring pain and muscle strains following anterior cruciate ligament reconstruction: a prospective, randomized trial comparing hamstring graft harvest techniques. J Knee Surg 2013;26:139-44.

18. Serpell BG, Scarvell JM, Ball NB, Smith PN. Mechanisms and risk factors for non-contact ACL injury in age mature athletes who engage in field or court sports: a summary of literature since 1980. J Strength Cond Res 2011;26:3160-76.

19. Bisciotti GN, Chamari K, Cena E, et al. Anterior cruciate ligament injury risk factors in football. J Sports Med Phys Fitness 2019; 59(10):1724-38.

20. Besier TF, Lloyd DG, Ackland TR. Muscle activation strategies at the knee during running and cutting maneuvers. Med Sci Sports Exerc 2003;35:119-27

21. Cochrane JL, Lloyd DG, Buttfield A, Seward H, McGivern J. Characteristics of anterior cruciate ligament injuries in Australian football. J Sci Med Sport 2007;10:96-104.

22. Zebis MK, Andersen LL, Bencke J, Kjær M, Aagaard P. Identification of athletes at future risk of anterior cruciate liga- ment ruptures by neuromuscular screening. Am J Sports Med 2009;37:1967-73.

23. Croisier JL, Forthomme B, Namurois MH, Vanderthommen M, Crielaard JM. Hamstring muscle strain recurrence and strength performance disorders. Am J Sports Med 2002;30:199-203.

24. Lee MJ, Reid SL, Elliott BC, Lloyd DG. Running biomechanics and lower limb strength associated with prior hamstring injury. Med Sci Sports Exerc 2009;41:1942-51.

25. Sole G, Milosavljevic S, Nicholson HD, Sullivan SJ. Selective strength loss and decreased muscle activity in hamstring injury. J Orthop Sports Phys Ther 2011;41:354-63.

26. Opar DA, Williams MD, Timmins RG, Dear NM, Shield AJ. Knee flexor strength and bicep femoris electromyographical activity is lower in previously strained hamstrings. J Electromyogr Kinesiol 2012;23:696-703.

27. Opar DA, Williams MD, Timmins RG, Dear NM, Shield AJ. Rate of torque and electromyographic development during anticipated eccentric contraction is lower in previously strained hamstrings. Am J Sports Med 2013;41:116-25.

28. Ahmad CS, ClarkAM,Heilmann N, Schoeb JS,GardnerTR, LevineWN. Effect of gender and maturity on quadriceps-to-hamstring strength ratio and anterior cruciate ligament laxity. Am J Sports Med 2006;34:370-4.

29. Blackburn JT, Bell DR, Norcross MF, Hudson JD, Engstrom LA. Comparison of hamstring neuromechanical properties between healthy males and females and the influence of musculotendinous stiffness. J Electromyogr Kinesiol 2009;19:362-9.

30. Malinzak RA, Colby SM, Kirkendall DT, Yu B, Garrett WE. A comparison of knee joint motion patterns between men and women in selected athletic tasks. Clin Biomech (Bristol, Avon) 2001;16:438-45.

31. Prodromos CC, Han Y, Rogowski J, Joyce B, Shi K. A meta-analysis of the incidence of anterior cruciate ligament tears as a function of gender, sport, and a knee injury-reduction regimen. Arthroscopy 2007;23:1320-1325.e6.

32. Smith HC, Vacek P, Johnson RJ, et al. Risk factors for anterior cruciate ligament injury: a review of the literature-part 2: hormonal, genetic, cognitive function, previous injury, and extrinsic risk factors. Sports Health 2012;4:155-61.

33. Sturnick DR, Vacek PM, DeSarno MJ, et al. Combined anatomic factors predicting risk of anterior cruciate ligament injury for males and females. Am J Sports Med 2015;43:839-47.

34. Bourne MN, Opar DA, Williams MD, et al. Eccentric knee flexor strength and risk of hamstring injuries in Rugby Union: a prospective study. Am J Sports Med 2015;43:2663-70.

35. Opar DA, Williams MD, Timmins RG, et al. Eccentric hamstring strength and hamstring injury risk in Australian footballers. Med Sci Sports Exerc 2015;47:857-65.

36. Weir A, Brukner P, Delahunt E, et al. Doha agreement meeting on terminology and definitions in groin pain in athletes. Br J Sports Med 2015;49(12):768-74.

37. Bisciotti GN, Volpi P, Zini R, et al. Groin Pain Syndrome Italian Consensus Conference on terminology, clinical evaluation and imaging assessment in groin pain in athlete. BMJ Open Sport Exerc Med 2016;2:e000142.

38. De Sa D, Hölmich P, Phillips M, et al. Athletic groin pain: a systematic review of surgical diagnoses, investigations and treatment. Br J Sports Med 2016;50(19):1181-6. 
39. Verrall GM, Slavotinek JP, Barnes PG, Esterman A, Oakeshott $\mathrm{RD}$, Spriggins AJ. Hip joint range of motion restriction precedes athletic chronic groin injury. J Sci Med Sport 2007;10(6):463-6.

40. Bisciotti GN, Di Marzo F, Auci A, Parra F, Cassaghi G, Corsini A, Petrera M, Volpi P, Vuckovic Z, Panascì M, Zini R. Cam morphology and inguinal pathologies: is there a possible connection? J Orthop Traumatol 2017;18(4):439-450.

41. Branch TP, Browne JE, Campbell JD, et al. Rotational laxity greater in patients with contralateral anterior cruciate ligament injury than healthy volunteers. Knee Surg Sports Traumatol Arthrosc 2010;18(10):1379-84.
42. Thomas AC, McLean SG, Palmieri-Smith RM. Quadriceps and hamstrings fatigue alters hip and knee mechanics. J Appl Biomech 2010;26(2):159-70.

43. Finch CF, Cook J. Categorising sports injuries in epidemiological studies: the subsequent injury categorisation (SIC) model to address multiple, recurrent and exacerbation of injuries. $\mathrm{Br} \mathrm{J}$ Sports Med 2014;48:1276-80.

44. Finch CF, Cook J, Gabbe BJ, et al. A new way of categorising recurrent, repeat and multiple sports injuries for injury incidence studies-the subsequent injury categorisation (SIC) model. Australasian Epidemiologist 2015;22:22-5. 